\title{
Adjacent-level arthroplasty following cervical fusion
}

\author{
Deshpande V. Rajakumar, MCh, Akshay Hari, MBBS, Murali Krishna, MCh, Subhas Konar, MCh, \\ and Ankit Sharma, MBBS
}

Department of Neurosurgery, Fortis Hospitals, Bangalore, India

\begin{abstract}
OBJECTIVE Adjacent-level disc degeneration following cervical fusion has been well reported. This condition poses a major treatment dilemma when it becomes symptomatic. The potential application of cervical arthroplasty to preserve motion in the affected segment is not well documented, with few studies in the literature. The authors present their initial experience of analyzing clinical and radiological results in such patients who were treated with arthroplasty for new or persistent arm and/or neck symptoms related to neural compression due to adjacent-segment disease after anterior cervical discectomy and fusion (ACDF).
\end{abstract}

METHODS During a 5-year period, 11 patients who had undergone ACDF anterior cervical discectomy and fusion (ACDF) and subsequently developed recurrent neck or arm pain related to adjacent-level cervical disc disease were treated with cervical arthroplasty at the authors' institution. A total of 15 devices were implanted (range of treated levels per patient: $1-3)$.

Clinical evaluation was performed both before and after surgery, using a visual analog scale (VAS) for pain and the Neck Disability Index (NDI). Radiological outcomes were analyzed using pre- and postoperative flexion/extension lateral radiographs measuring Cobb angle (overall C2-7 sagittal alignment), functional spinal unit (FSU) angle, and range of motion (ROM).

RESULTS There were no major perioperative complications or device-related failures. Statistically significant results, obtained in all cases, were reflected by an improvement in VAS scores for neck/arm pain and NDI scores for neck pain. Radiologically, statistically significant increases in the overall lordosis (as measured by Cobb angle) and ROM at the treated disc level were observed. Three patients were lost to follow-up within the first year after arthroplasty. In the remaining 8 cases, the duration of follow-up ranged from 1 to 3 years. None of these 8 patients required surgery for the same vertebral level during the follow-up period.

CONCLUSIONS Artificial cervical disc replacement in patients who have previously undergone cervical fusion surgery appears to be safe, with encouraging early clinical results based on this small case series, but more data from larger numbers of patients with long-term follow-up are needed. Arthroplasty may provide an additional tool for the management of post-fusion adjacent-level cervical disc disease in carefully selected patients.

https://thejns.org/doi/abs/10.3171/2016.11.FOCUS16412

KEY WORDS adjacent-segment disease; cervical disc degeneration; arthroplasty; anterior cervical discectomy and fusion

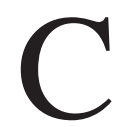
ERVICAL degenerative disc disease is a common condition in a clinical neurosurgery practice. Symptoms ranging from radiculopathy to myelopathy have been managed well with anterior cervical discectomy and fusion (ACDF), which has been accepted as a "gold standard" surgical treatment for the last 50 years. ${ }^{5,22}$ Various reports have demonstrated that adjacent-segment degeneration (ASD) may occur following spinal fusion. ${ }^{12-14}$
Over the past few decades, various studies, both clinical and cadaveric, have provided evidence to suggest that inherent kinematic and biomechanical issues due to fusion may be responsible for ASD. ${ }^{9,17}$ Recently, there has been much debate as to the proper management of ASD following fusion, with total artificial disc replacement emerging as a radical, albeit controversial, solution. ${ }^{16}$

In this regard, we attempted to analyze data from a

ABBREVIATIONS ACDF = anterior cervical discectomy and fusion; ASD = adjacent-segment degeneration; FSU = functional spinal unit; NDI = Neck Disability Index; ROM $=$ range of motion; VAS = visual analog scale. 
TABLE 1. Summary of patients' clinical and demographic characteristics

\begin{tabular}{ccllccl}
\hline $\begin{array}{c}\text { Case } \\
\text { No. }\end{array}$ & $\begin{array}{c}\text { Age (yrs), } \\
\text { Sex }\end{array}$ & $\begin{array}{c}\text { Fused } \\
\text { Segment }\end{array}$ & $\begin{array}{c}\text { Fusion } \\
\text { Type }\end{array}$ & $\begin{array}{c}\text { Yrs Since } \\
\text { Fusion Surgery }\end{array}$ & $\begin{array}{c}\text { Duration of Recurrent } \\
\text { Symptoms (mos) }\end{array}$ & Arthroplasty \\
\hline 1 & $64, \mathrm{M}$ & C5-6, C6-7 & Plated & 9 & 18 & 2-level: C4-5, C7-T1 \\
\hline 2 & $57, \mathrm{M}$ & C5-6 & Non-plated & 25 & 6 & 1-level: C6-7 \\
\hline 3 & $60, \mathrm{~F}$ & C5-6, C6-7 & Non-plated & 22 & 72 & 3-level: C3-4, C4-5, C7-T1 \\
\hline 4 & $39, \mathrm{M}$ & C3-4 & Non-plated & 8 & 6 & 2-level: C4-5, C5-6 \\
\hline 5 & $61, \mathrm{M}$ & C5-6 & Plated & 8 & 24 & 1-level: C4-5 \\
\hline 6 & $44, \mathrm{~F}$ & C5-6 & Non-plated & 9 & 8 & 1-level: C6-7 \\
\hline 7 & $37, \mathrm{M}$ & C5-6, C6-7 & Plated & 6 & 4 & 1-level: C4-5 \\
\hline 8 & $46, \mathrm{M}$ & C5-6, C6-7 & Non-plated & 7 & 9 & 1-level: C4-5 \\
\hline 9 & $49, \mathrm{M}$ & C4-5 & Non-plated & 11 & 6 & 1-level: C5-6 \\
\hline 10 & $51, \mathrm{M}$ & C4-5 & Non-plated & 9 & 12 & 1-level: C5-6 \\
\hline 11 & $56, \mathrm{M}$ & C5-6 & Non-plated & 13 & 7 & 1-level: C4-5 \\
\hline
\end{tabular}

small cohort of patients who had undergone arthroplasty for the treatment of post-ACDF new or recurrent neck/arm symptoms corresponding to adjacent-level degeneration confirmed on MRI. In this paper, we present our initial experience with such patients.

\section{Methods}

A total of 11 patients ( 9 men and 2 women) were identified who had undergone ACDF procedures previously and had subsequently been treated with arthroplasty for ASD in our department between 2009 and 2015. Data on these cases were obtained from a review of the patients' medical records. The patients' age at the time of arthroplasty ranged from 37 to 64 years. The fusion surgeries performed earlier included plate placement in 3 patients while the other patients underwent ACDF procedures without instrumentation. A summary of the patients' demographic and clinical characteristics is presented in Table 1.

These patients belonged to a small subgroup who had prior cervical fusion surgeries and had recurrent debilitating arm/neck pain that was not relieved with many years of conservative/nonoperative therapy and which was significantly affecting their quality of life. The option of arthroplasty was offered to these patients after confirmation of radiographic evidence of significant cervical adjacentsegment disc degeneration, with no instability or facetal degeneration or canal stenosis. All surgeries were performed by the senior author (D.V.R.).

Preoperative cervical imaging with MRI and radiography (including dynamic studies) was performed routinely. Surgery was suggested when significant degeneration and neural compression were observed at levels adjacent to previously fused segments. Normally, these patients would have qualified for and been offered a second ACDF procedure. Exclusion criteria included significant kyphosis, severe multilevel spondylotic disc degeneration, and spinal cord injury with possible instability,

A detailed neurological examination was performed preoperatively in all cases. Clinical evaluation was performed both before and after surgery, and visual analog scale (VAS) pain and the Neck Disability Index (NDI) scores were obtained at both time points. Radiological outcomes were analyzed using pre- and postoperative flexion/extension lateral radiographs measuring Cobb angle (overall cervical sagittal alignment expressed as the C2-7 angle), functional spinal unit (FSU) angle, and range of motion (ROM). Kyphosis was represented by a negative value and lordosis by a positive value.

Standard operative techniques were used as described elsewhere. ${ }^{20}$ After induction of general anesthesia, surgery was performed in the neutral supine position under fluoroscopic guidance. No collar therapy was necessary postoperatively. The patients were given analgesics and 3 doses of antibiotics on the day after surgery. Postoperative evaluations incorporated the same clinical and radiological evaluations that were performed preoperatively.

Statistical analysis was performed using Wilcoxon's test for clinical assessments and paired t-tests for radiological assessments. A probability value less than 0.05 was regarded as significant.

\section{Results}

A total of 15 artificial discs (Prestige LP, Medtronic) were inserted at the level of cervical disc degeneration adjacent to the index fusion in 11 patients. The number of levels treated with arthroplasty in any given patient ranged from 1 to 3 (Table 1). There were no major perioperative complications, immediate device-related failures, or neurological injuries. Minor complications included mild dysphagia in 1 patient and hoarseness of voice in another, both of which were found to have fully resolved at subsequent follow-up. Arthroplasty was not converted to a fusion procedure intraoperatively in any of the 11 cases, and no patient required any reoperation at the same level during follow up. Normal motion was maintained at the most recent follow-up evaluation in all cases.

The overall mean duration of follow-up was 14.5 months (range 1-38 months, see Table 5 for duration of follow-up for each patient). Three patients (each with only 1 treated level) were lost to follow-up at less than 1 year after arthroplasty.

The results of analysis of preoperative and postoperative clinical and radiographic values are represented in Table 2 and Table 3, respectively. 
TABLE 2. Standardized clinical outcome measures

\begin{tabular}{cccccccc}
\hline \multirow{2}{*}{$\begin{array}{c}\text { Case } \\
\text { No. }\end{array}$} & \multicolumn{3}{c}{ VAS Pain Score } & & \multicolumn{3}{c}{ NDI } \\
\cline { 2 - 3 } \cline { 6 - 7 } & Preop & Postop & $1 \mathrm{Yr}$ & & Preop & Postop & $1 \mathrm{Yr}$ \\
\hline 1 & 7 & 3 & 2 & & 52 & 20 & 12 \\
\hline 2 & 5 & 2 & 1 & & 48 & 16 & 10 \\
\hline 3 & 6 & 2 & 0 & 35 & 12 & 10 \\
\hline 4 & 6 & 1 & 0 & 58 & 33 & 20 \\
\hline 5 & 7 & 2 & - & 70 & 25 & - \\
\hline 6 & 7 & 4 & 0 & 62 & 46 & 14 \\
\hline 7 & 5 & 4 & 2 & 61 & 21 & 18 \\
\hline 8 & 7 & 2 & 1 & 80 & 30 & 20 \\
\hline 9 & 5 & 1 & 1 & 46 & 20 & 10 \\
\hline 10 & 6 & 2 & - & 58 & 10 & - \\
\hline 11 & 7 & 1 & - & 76 & 16 & - \\
\hline Mean & 6.18 & 2.18 & 0.87 & 58.73 & 22.64 & 14.25 \\
\hline SD & 0.87 & 1.08 & 0.83 & 13.34 & 10.44 & 4.46 \\
\hline p value & & $<0.001$ & $<0.0001$ & & $<0.001$ & $<0.0001$ \\
\hline
\end{tabular}

\section{Clinical Analysis}

After arthroplasty, pain was reduced overall, as reflected by an improvement in the mean VAS score from 6.18 preoperatively to 2.18 in the immediate postoperative period $(n=11)$ and further reduction to $0.87(\mathrm{n}=8)$ at 1 year's follow-up $(\mathrm{p}<0.0001)$. The mean NDI score improved from 58.7 to 22.6 in the immediate postoperative period $(\mathrm{n}=11)$ and then to 14.25 at 1 year after surgery $(\mathrm{n}$ $=8$ ), which was also a statistically significant change ( $<$ $0.0001)$. The preoperative and final follow-up mean scores are also represented in Fig. 1.
TABLE 3. Radiological analysis: radiographic values obtained in 11 cases

\begin{tabular}{|c|c|c|c|c|c|}
\hline \multirow[b]{2}{*}{ Variable } & \multicolumn{2}{|c|}{ Preop } & \multicolumn{2}{|c|}{ Postop† } & \multirow{2}{*}{$\begin{array}{c}p \\
\text { Value* }\end{array}$} \\
\hline & Mean & SD & Mean & SD & \\
\hline Cobb angle & $3.36^{\circ}$ & $7.78^{\circ}$ & $7.58^{\circ}$ & $8.42^{\circ}$ & $<0.01$ \\
\hline FSU & $2.47^{\circ}$ & $6.01^{\circ}$ & $4.14^{\circ}$ & $6.27^{\circ}$ & 0.64 \\
\hline ROM & $5.14^{\circ}$ & $4.36^{\circ}$ & $7.56^{\circ}$ & $4.84^{\circ}$ & $<0.01$ \\
\hline
\end{tabular}

* Based on paired t-test.

$\dagger$ Immediate postoperative.

\section{Radiological Analysis}

Quantitative analysis of imaging findings obtained in the entire group (Table 4) showed substantial differences in pre- and postoperative sagittal alignment in the neutral position as measured by the mean Cobb angle (from C-2 to C-7), suggesting that preoperative sagittal balance was not only preserved but even enhanced after arthroplasty.

The mean cervical ROM improved significantly after surgery (mean $5.14^{\circ}$ vs $7.56^{\circ}$ for preoperative and immediate postoperative ROM, respectively, at 15 levels in 11 patients, $\mathrm{p}<0.01$ ), suggesting that the artificial disc replacement provided for additional "lost" movement at the degenerated disc level, thereby contributing to the overall Cobb angle and an improved sagittal balance.

Radiological follow up at 1-year was available for $8 \mathrm{pa}-$ tients. Comparison of the mean ROM at the treated levels in these patients (12 levels in 8 patients) at 1 year after arthroplasty was not significantly different from the mean value for immediate postoperative ROM (based on $15 \mathrm{lev}$ els in 11 patients) $(\mathrm{p}=0.81$, Table 5). One patient had 3 years of follow-up with no deterioration in ROM.
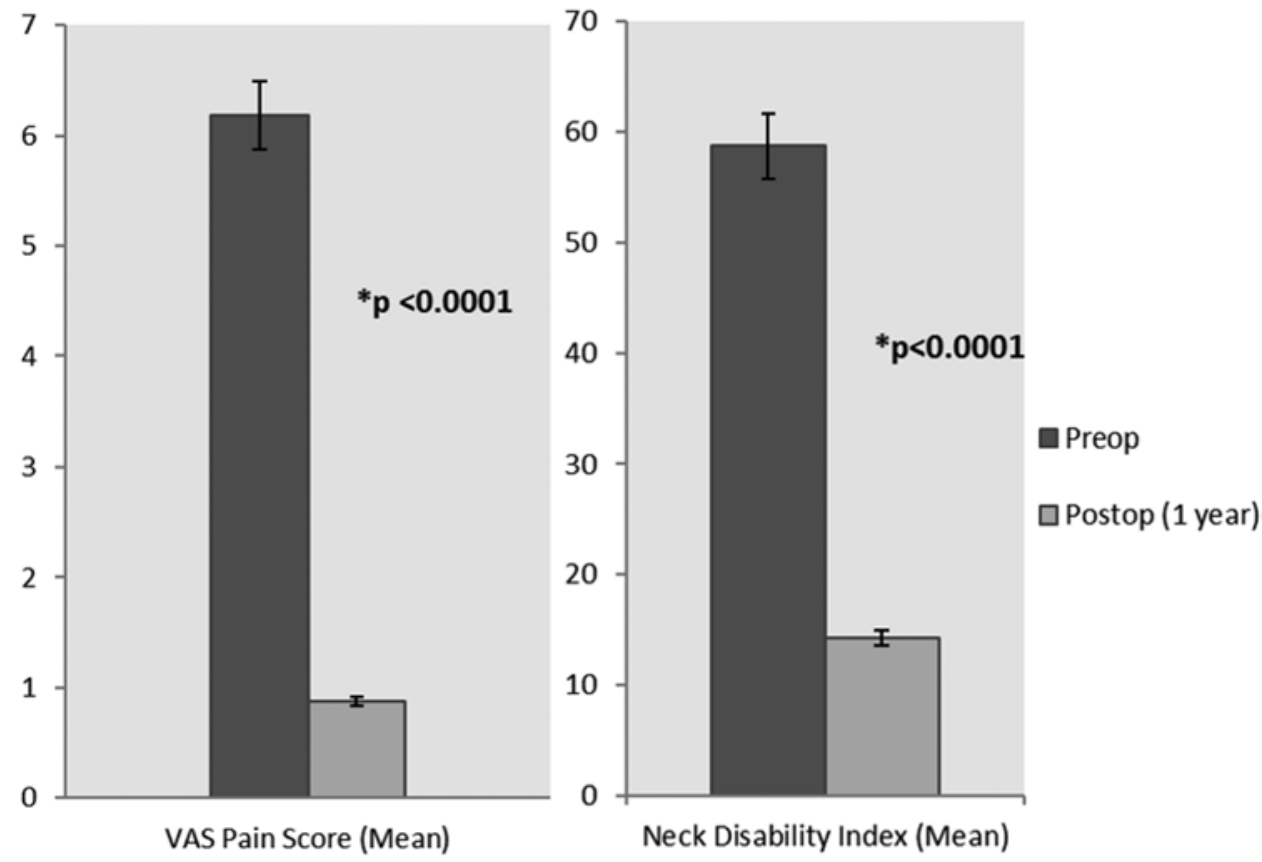

FIG. 1. Graphs showing the mean VAS (left) and NDI (right) pain scores before arthroplasty $(n=11)$ and 1 year after arthroplasty $(\mathrm{n}=8)$. Error bars indicate SDs. 
TABLE 4. Quantitative analysis of radiological findings in 11 patients who underwent arthroplasty at 15 levels

\begin{tabular}{|c|c|c|c|c|c|c|}
\hline \multirow[b]{2}{*}{$\begin{array}{c}\text { Case } \\
\text { No. }\end{array}$} & \multicolumn{3}{|c|}{ Preop } & \multicolumn{3}{|c|}{ Postop } \\
\hline & $\begin{array}{l}\text { Cobb } \\
\text { Angle }\end{array}$ & $\begin{array}{l}\text { FSU } \\
\text { Angle }\end{array}$ & ROM & $\begin{array}{l}\text { Cobb } \\
\text { Angle }\end{array}$ & $\begin{array}{c}\text { FSU } \\
\text { Angle }\end{array}$ & ROM \\
\hline \multirow{2}{*}{1} & $11.4^{\circ}$ & $10.7^{\circ}$ & $3^{\circ}$ & $15.4^{\circ}$ & $13.3^{\circ}$ & $11.5^{\circ}$ \\
\hline & $11.4^{\circ}$ & $10.7^{\circ}$ & $1.8^{\circ}$ & $15.4^{\circ}$ & $11.4^{\circ}$ & $3.3^{\circ}$ \\
\hline 2 & $10.2^{\circ}$ & $-3.3^{\circ}$ & $3.1^{\circ}$ & $17.7^{\circ}$ & $0.5^{\circ}$ & $5^{\circ}$ \\
\hline \multirow{3}{*}{3} & $-4.6^{\circ}$ & $-4.5^{\circ}$ & $7.8^{\circ}$ & $-2.2^{\circ}$ & $3.7^{\circ}$ & $9.7^{\circ}$ \\
\hline & $-4.6^{\circ}$ & $5^{\circ}$ & $14^{\circ}$ & $-2.2^{\circ}$ & $-2.3^{\circ}$ & $18.6^{\circ}$ \\
\hline & $-4.6^{\circ}$ & $5.6^{\circ}$ & $4.7^{\circ}$ & $-2.2^{\circ}$ & $-2.5^{\circ}$ & $5.3^{\circ}$ \\
\hline \multirow{2}{*}{4} & $-0.9^{\circ}$ & $-3.7^{\circ}$ & $5.9^{\circ}$ & $5^{\circ}$ & $-1.9^{\circ}$ & $9.2^{\circ}$ \\
\hline & $-0.9^{\circ}$ & $-3.3^{\circ}$ & $14.2^{\circ}$ & $5^{\circ}$ & $-1.4^{\circ}$ & $14.8^{\circ}$ \\
\hline 5 & $19.2^{\circ}$ & $14.4^{\circ}$ & $0.9^{\circ}$ & $20.2^{\circ}$ & $18.4^{\circ}$ & $1.6^{\circ}$ \\
\hline 6 & $6.9^{\circ}$ & $2.5^{\circ}$ & $8.3^{\circ}$ & $13.5^{\circ}$ & $3.7^{\circ}$ & $11.3^{\circ}$ \\
\hline 7 & $-3.6^{\circ}$ & $-1.9^{\circ}$ & $6.3^{\circ}$ & $-0.4^{\circ}$ & $2.4^{\circ}$ & $6.6^{\circ}$ \\
\hline 8 & $-3.2^{\circ}$ & $1.2^{\circ}$ & $0.7^{\circ}$ & $-0.6^{\circ}$ & $6.5^{\circ}$ & $2.7^{\circ}$ \\
\hline 9 & $12^{\circ}$ & $2.9^{\circ}$ & $1.8^{\circ}$ & $19^{\circ}$ & $5.5^{\circ}$ & $4^{\circ}$ \\
\hline 10 & $-0.7^{\circ}$ & $-3.5^{\circ}$ & $3.4^{\circ}$ & $4.6^{\circ}$ & $-1.3^{\circ}$ & $5.8^{\circ}$ \\
\hline 11 & $2.5^{\circ}$ & $4.3^{\circ}$ & $1.2^{\circ}$ & $5.6^{\circ}$ & $6.2^{\circ}$ & $4.1^{\circ}$ \\
\hline Mean & $3.36^{\circ}$ & $2.47^{\circ}$ & $5.14^{\circ}$ & $7.58^{\circ}$ & $4.14^{\circ}$ & $7.56^{\circ}$ \\
\hline SD & $7.78^{\circ}$ & $6.01^{\circ}$ & $4.36^{\circ}$ & $8.42^{\circ}$ & $6.27^{\circ}$ & $4.84^{\circ}$ \\
\hline
\end{tabular}

The patients in Cases 1, 3, and 4 underwent multilevel arthroplasty. Data are provided for each treated level. Negative values represent kyphosis, and positive values represent lordosis.

There was no statistically significant improvement in the mean FSU angle ( $p=0.64$ for comparison of preoperative and immediate postoperative values), probably due to the involvement of adjacent fused levels and varying numbers of fused segments.

An illustrative example of the various radiological measurements is represented in Fig. 2.

\section{Discussion}

Surgical management of ASD is a highly controversial topic, with both anterior and posterior approaches showing excellent results. ${ }^{16}$ While the number of ACDF surgeries for treatment of primary cervical disc degeneration shows an ever-rising trend, there is also a concomitant increase in the associated phenomenon of ASD-with studies showing a prevalence of approximately $25 \%$ at 10 years after surgery. ${ }^{10,24}$ Furthermore, almost $15 \%$ of patients require a second surgery, with some reports of even a third surgery following treatment with a second ACDF. ${ }^{4}$ This suggests that ASD is an ongoing process due to altered biomechanics of the spine, probably closely related to the natural history of disc degeneration per se and further accentuated by iatrogenic intervention. ${ }^{1,10,16}$

With the option of arthroplasty, there is a theoretical assumption that reconstructing normal or near normal spinal biomechanics should diminish chances of further spinal degeneration and thus the development of ASD. ${ }^{2,3,6-}$ $8,11,15,18,19,21,23$

Our study provides evidence supporting the hypothesis that arthroplasty may indeed be an alternative solution in a certain carefully selected cohort of ASD patients in whom conservative therapy has failed. Our results show that adequate decompression can be achieved along with improvement in the overall sagittal profile (as seen by an increase in cervical lordosis) due to an increase in the disc space angle and ROM at the treated level.

\section{Conclusions}

Arthroplasty for ASD following cervical fusion provides an alternative option for treatment in this subset of patients, raising the possibility of preserving motion in patients who otherwise would have undergone a fusion procedure. It may be reserved for those who 1) have debilitating pain significantly affecting their daily life and 2) have followed a regimen of conservative treatment for many months without adequate relief.

The current study was performed as a pilot proof of concept study and demonstrates good clinical and radiological results in treating ASD with arthroplasty. Further studies with longer follow-up and larger sample sizes are

TABLE 5. Follow-up data from 11 cases

\begin{tabular}{cllcc}
\hline Case No. & Prior Fusion & \multicolumn{1}{c}{ Arthroplasty } & Follow-Up (mos) & ROM (at 1 yr) \\
\hline 1 & C5-6, C6-7 & 2-level: C4-5, C7-T1 & 38 & $10.7^{\circ}, 3.5^{\circ}$ \\
\hline 2 & C5-6 & 1-level: C6-7 & 26 & $5.4^{\circ}$ \\
\hline 3 & C5-6, C6-7 & 3-level: C3-4, C4-5, C7-T1 & 13 & $9.5^{\circ}, 17.3^{\circ}, 5.8^{\circ}$ \\
\hline 4 & C3-4 & 2-level: C4-5, C5-6 & 14 & $9.8^{\circ}, 14.5^{\circ}$ \\
\hline 5 & C5-6 & 1-level: C4-5 & 6 & - \\
\hline 6 & C5-6 & 1-level: C6-7 & 12 & $10.8^{\circ}$ \\
\hline 7 & C5-6, C6-7 & 1-level: C4-5 & 14 & $3.9^{\circ}$ \\
\hline 8 & C5-6, C6-7 & 1-level: C4-5 & 18 & $3.1^{\circ}$ \\
\hline 9 & C4-5 & 1-level: C5-6 & 12 & $4.2^{\circ}$ \\
\hline 10 & C4-5 & 1-level: C5-6 & 6 & - \\
\hline 11 & C5-6 & 1-level: C4-5 & 1 & - \\
\hline
\end{tabular}

The mean duration of follow-up was 14.5 months. There was no statistically significant difference $(p=0.81)$ between the mean ROM at 1 year after arthroplasty (based on 12 treated levels in 8 patients) and the mean ROM immediately after arthroplasty (based on 15 treated levels in 11 patients). 


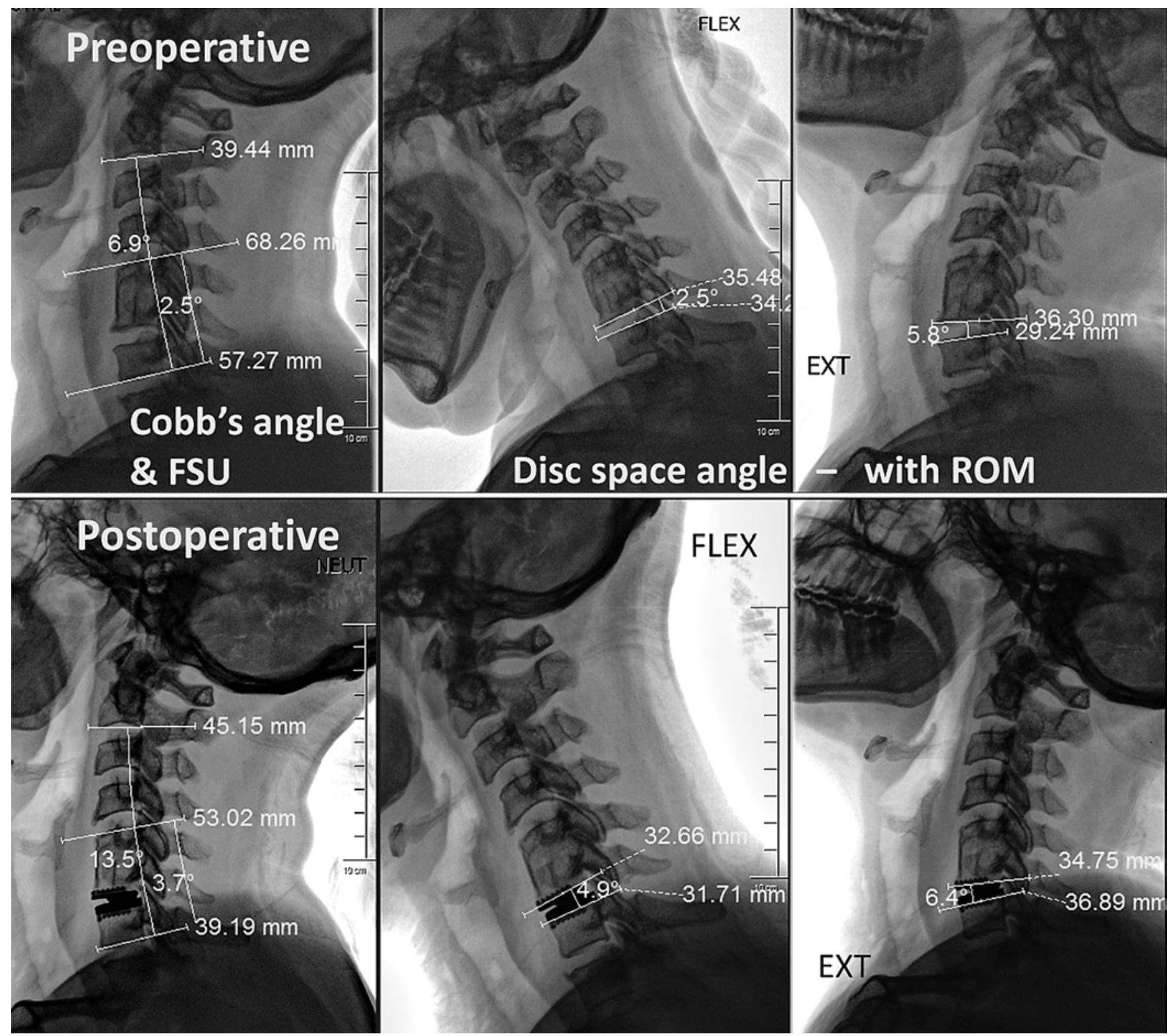

FIG. 2. Representative pre- and postoperative lateral neutral dynamic radiographs (from Case 6) showing the radiological parameters of Cobb angle, FSU angle, and ROM.

required to determine whether such a procedure will be beneficial in the long term.

\section{Acknowledgments}

We would like to acknowledge Clare Claiton, MSc, for her help in preparation of the manuscript.

\section{References}

1. Acikbas SC, Ermol C, Akyuz M, Tuncer R: Assessment of adjacent segment degeneration in and between patients treated with anterior or posterior cervical simple discectomy. Turk Neurosurg 20:334-340, 2010

2. Burkus JK, Haid RW, Traynelis VC, Mummaneni PV: Longterm clinical and radiographic outcomes of cervical disc replacement with the Prestige disc: results from a prospective randomized controlled clinical trial. J Neurosurg Spine 13:308-318, 2010

3. Burkus JK, Traynelis VC, Haid RW Jr, Mummaneni PV: Clinical and radiographic analysis of an artificial cervical disc: 7-year follow-up from the Prestige prospective randomized controlled clinical trial: clinical article. J Neurosurg Spine 21:516-528, 2014

4. Bydon M, Xu R, Macki M, De la Garza-Ramos R, Sciubba DM, Wolinsky JP, et al: Adjacent segment disease after anterior cervical discectomy and fusion in a large series. Neurosurgery 74:139-146, 2014

5. Cloward RB: The anterior approach for removal of ruptured cervical disks. J Neurosurg 15:602-617, 1958

6. Coric D, Finger F, Boltes P: Prospective randomized controlled study of the Bryan Cervical Disc: early clinical results from a single investigational site. J Neurosurg Spine 4:31-35, 2006 
7. Coric D, Nunley PD, Guyer RD, Musante D, Carmody CN Gordon CR, et al: Prospective, randomized, multicenter study of cervical arthroplasty: 269 patients from the Kineflex|C artificial disc investigational device exemption study with a minimum 2-year follow-up: clinical article. J Neurosurg Spine 15:348-358, 2011

8. DiAngelo DJ, Foley KT, Morrow BR, Schwab JS, Song J, German JW, et al: In vitro biomechanics of cervical disc arthroplasty with the ProDisc-C total disc implant. Neurosurg Focus 17(3):E7, 2004

9. Eck JC, Humphreys SC, Lim TH, Jeong ST, Kim JG, Hodges $\mathrm{SD}$, et al: Biomechanical study on the effect of cervical spine fusion on adjacent-level intradiscal pressure and segmental motion. Spine (Phila Pa 1976) 27:2431-2434, 2002

10. Gore DR, Sepic SB: Anterior discectomy and fusion for painful cervical disc disease. A report of 50 patients with an average follow-up of 21 years. Spine (Phila Pa 1976) 23:2047-2051, 1998

11. Heller JG, Sasso RC, Papadopoulos SM, Anderson PA, Fessler RG, Hacker RJ, et al: Comparison of BRYAN cervical disc arthroplasty with anterior cervical decompression and fusion: clinical and radiographic results of a randomized, controlled, clinical trial. Spine (Phila Pa 1976) 34:101-107, 2009

12. Hilibrand AS, Carlson GD, Palumbo MA, Jones PK, Bohlman HH: Radiculopathy and myelopathy at segments adjacent to the site of a previous anterior cervical arthrodesis. J Bone Joint Surg Am 81:519-528, 1999

13. Hilibrand AS, Robbins M: Adjacent segment degeneration and adjacent segment disease: the consequences of spinal fusion? Spine J 4 (6 Suppl):190S-194S, 2004

14. Ishihara H, Kanamori M, Kawaguchi Y, Nakamura H, Kimura T: Adjacent segment disease after anterior cervical interbody fusion. Spine J 4:624-628, 2004

15. Jawahar A, Cavanaugh DA, Kerr EJ III, Birdsong EM, Nunley PD: Total disc arthroplasty does not affect the incidence of adjacent segment degeneration in cervical spine: results of 93 patients in three prospective randomized clinical trials. Spine J 10:1043-1048, 2010

16. Kepler CK, Hilibrand AS: Management of adjacent segment disease after cervical spinal fusion. Orthop Clin North Am 43:53-62, viii, 2012

17. Kretzer RM, Hsu W, Hu N, Umekoji H, Jallo GI, McAfee PC, et al: Adjacent-level range of motion and intradiscal pressure after posterior cervical decompression and fixation: an in vitro human cadaveric model. Spine (Phila Pa 1976) 37:E778-E785, 2012

18. Mummaneni PV, Burkus JK, Haid RW, Traynelis VC, Zdeblick TA: Clinical and radiographic analysis of cervical disc arthroplasty compared with allograft fusion: a randomized controlled clinical trial. J Neurosurg Spine 6:198-209, 2007

19. Mummaneni PV, Robinson JC, Haid RW: Cervical arthroplasty with the PRESTIGE LP cervical disc. Neurosurgery 60 (4 Suppl 2):310-315, 2007
20. Peng CWB, Yue WM, Basit A, Guo CM, Tow BPB, Chen JLT, et al: Intermediate results of the Prestige LP cervical disc replacement: clinical and radiological analysis with minimum two-year follow-up. Spine (Phila Pa 1976) 36:E105E111, 2011

21. Radcliff K, Coric D, Albert T: Five-year clinical results of cervical total disc replacement compared with anterior discectomy and fusion for treatment of 2-level symptomatic degenerative disc disease: a prospective, randomized, controlled, multicenter investigational device exemption clinical trial. J Neurosurg Spine 25:213-224, 2016

22. Smith GW, Robinson RA: The treatment of certain cervicalspine disorders by anterior removal of the intervertebral disc and interbody fusion. J Bone Joint Surg Am 40-A:607-624, 1958

23. Upadhyaya CD, Wu JC, Trost G, Haid RW, Traynelis VC, Tay B, et al: Analysis of the three United States Food and Drug Administration investigational device exemption cervical arthroplasty trials. J Neurosurg Spine 16:216-228, 2012

24. Yue WM, Brodner W, Highland TR: Long-term results after anterior cervical discectomy and fusion with allograft and plating: a 5- to 11-year radiologic and clinical follow-up study. Spine (Phila Pa 1976) 30:2138-2144, 2005

\section{Disclosures}

The authors report no conflict of interest concerning the materials or methods used in this study or the findings specified in this paper.

\section{Author Contributions}

Conception and design: Rajakumar. Acquisition of data: Rajakumar, Hari. Analysis and interpretation of data: Rajakumar, Hari. Drafting the article: Rajakumar, Hari, Krishna, Konar. Critically revising the article: Rajakumar, Hari, Krishna, Konar. Reviewed submitted version of manuscript: Rajakumar, Hari, Krishna, Konar. Approved the final version of the manuscript on behalf of all authors: Rajakumar. Statistical analysis: Rajakumar, Hari, Krishna, Konar. Administrative/technical/material support: Rajakumar, Hari, Sharma. Study supervision: Rajakumar.

\section{Supplemental Information \\ Videos \\ Video abstract. https://vimeo.com/198045610.}

\section{Correspondence}

Deshpande V. Rajakumar, Department of Neurosurgery, Fortis Hospitals, \#154/9, Opp. IIM-B, Bannerghatta Rd., Bangalore 560076, India. email: drajakumar9@gmail.com. 